\title{
Institutional Environment, Government Intervention, and the Performance of High-tech Zones Empirical Evidence from Transition Economy
}

\author{
Xiong Ke \\ Management School, Jinan University \\ Franchise Management School, Beijing Normal University, Zhuhai Campus \\ Jin Feng Road, Tang jia wan, Zhuhai 519087, China \\ Tel: 86-756-612-6520Ｅ-mail: xkcs@163.com \\ Xiwei Yi \\ Guanghua School of Management, Peking University \\ NO.5 Yiheyuan Road, Haidian District, Beijing 100871, China \\ E-mail: yixiwei.1989@hotmail.com \\ Xiaolong Liu \\ A.T. Kearney China \\ Room 2608, 26th Floor Buiding 2, Hua Mao Center No.79 \\ Jian Guo Road, Beijing 100025, China \\ E-mail: xiliuz@sina.com.cn \\ Zhuoqi Li \\ College of Arts, Jinan University \\ No.601, Huangpu Road (West), GuangZhou, GuangDong, 510632, China \\ E-mail:tammy89@163.com
}

Received: November 9, 2011

Accepted: December 1, 2011

Published: February16, 2012

doi:10.5539/ijbm.v7n4p112

URL: http://dx.doi.org/10.5539/ijbm.v7n4p112

\begin{abstract}
High-tech zones emerged as a way to manage, design and promote local high-technology entrepreneurship. Extant theories have elaborated the underlying mechanism of high-tech zones from Industries Cluster Perspective, Transaction Cost Theory and Social Capital Theory. However, these analyses are mainly conducted under the developed markets where institutional environment is comparatively perfect. While high-tech zones are now increasingly a popular adoption in transition economy, limited literature has investigated the characteristics of high-tech zones under such economy. In this paper, we studied how institutional imperfection, mainly characterized as government intervention, exerts an adverse impact on the performance of high-tech zones. Using the data of Chinese National High-tech Zones from 2006-2007, the empirical results support our hypotheses that government intervention influences the performance of high-tech zones through the degree of duplicate constructions and the quality of in-zone industrial configuration.
\end{abstract}

Keywords: Institutional environment, Government intervention, Transitional economy

\section{Introduction}

High-tech zones firstly caught scholars' attention when Silicon Valley in United States, Tsukuba high-tech zones in Japan and et al. demonstrate their excellent capability in facilitating knowledge transfer and promoting 
high-tech entrepreneurship. The concept of high-tech zones derived in 1950s and its main aim is to promote high-tech entrepreneurship by providing a technical, logistical, administrative and financial infrastructure to assist new ventures to gain a toehold in the increasingly competitive markets (Lai and Shyu, 2005). Extant theories mainly elaborated the underlying mechanism of high-tech zones from Social Capital Theory (Saxenian, 2001), Transaction Cost Theory and Industries Cluster Perspective (Kenney and Burg, 1999, B.Harrison, 1992). However, such analyses are mainly conducted under the developed markets where institutional environment is comparatively complete and perfect. While nowadays high-tech zones are now increasingly a popular adoption in transition economy, it is crucial to recognize the previous negligible question that the performance determinants of high-tech zones vary a lot across different countries such as government policy, legal rules, capital market conditions and factor costs (Porter, 1990). In this paper, we aim to fill such gaps by examining how institutional environment imperfection, characterized mainly as government intervention here, exerts an adverse influence on the performance of high-tech zones in transition economies. We focused our research on Chinese High-tech zones since China provides a rich research context as its transition from a planned economy characterized as rigorous government control to a market economy which publicize free competition. Such a research context enables us to investigate thoroughly under what mechanisms the imperfections of institutional environment influence the performance of high-tech zones.

In China, instead of being a spontaneous assemblage, high-tech zones are often established as a policy instruments aimed at promoting regional research-based industrial and innovative activities and usually obtains considerable resource sponsor from regional government. Therefore, as a particular product of the special administration and taxation systems in China, the performance of high-tech zones is more than an integrated function of social capital and industry cluster perspective. To understand the arbitrariness, complexity and volatility manifested in the development pattern of Chinese high-tech zones, we have to reveal the influence of government intervention to gain a more comprehensive picture about high-tech zones. By investigating the behavior of regional government, we suggested government intervention mainly influences the performance of high-tech zones through two mechanisms, one is the duplicate constructions and the other is the in-zone industrial configuration. Using the Chinese National High-tech Zones data in 2006 and 2007, we empirically test our hypothesis and the result supports a negative relationship between the regional GDP level and the degree of duplicate constructions and further a negative relationship between the degree of duplicate constructions and the performance of high-tech zones. The empirical result also supports the second mechanism that the pressure to attract investment for high-tech zones is negatively related to the quality of in-zone industrial configuration, which is positively related to the performance of the high-tech zones.

\section{Discussions and Hypothesis}

\subsection{Promotion Tournament, Duplicate Construction and Performance Implication}

Chinese regional governments play an important role in stimulating the dramatic economic growth by allocating a large proportion of attention to regional economic development. Such motivations originate from the current "promotion tournament system" (Zhou, 2007), which refers to China's current political promotion system emphasizing regional economic performance. Such a concept implies the competitions for economic achievement among regional government officials are as fierce as tournaments. Under such promotion system, we suggested that, induced by the promotion rewards and pressed by the peer performance, regional governments who suffer from low GDP level have strong incentives to fake the economic performance by building more high-tech zones since the number of high-tech zones is an indicator of local economic performance and such projects temporarily alleviate local employment pressure. However, such unscrupulous decisions motivated by political interest will leads to the duplicate constructions of high-tech zones in local areas. We develop the following model to clarify our proposition.

Assuming the central government's decision represents the social optimization and the central government $t$ is in charge of $\mathrm{n}$ regional governments. The regional government $\mathrm{i}$ decides the number of high-tech zones (holding size the same) built in the local area as $g(i=1,2 \cdots ; n)$. Then for the central government the sum of the number of regional high-tech zones is $G=\sum g_{i}$. Suppose $\mathrm{v}$ is the economic return brought by one high-tech zone and the value of $\mathrm{v}$ is obviously related to the sum number $\mathrm{G}$, then the function of $\mathrm{v}$ is $v=v(G)$ and according to the law of diminishing marginal utility the function $v=v(G)$ satisfies the following condition:

$$
\frac{\partial v}{\partial G}<0, \frac{\partial^{2} v}{\partial G^{2}}<0
$$

In this model, the decision for regional government is to choose an optimal number of high-tech zones to maximize the regional economic performance. Suppose the up-font development cost to build a high-tech zone 
is $c$, then the profit function should be:

$$
\pi_{i}\left(g_{1}, \cdots, g_{i}, \cdots, g_{n}\right)=g_{i} v(G)-g_{i} c \quad i=1,2, \cdots, n
$$

The F.O.C condition of the above equation is:

$$
\frac{\partial \pi_{i}}{\partial g_{i}}=v(G)+g_{i} v^{\prime}(G)-c=0 \quad i=1,2, \cdots, n
$$

The F.O.C condition implies that increasing the number of high-tech zones exerts two contradictory influences. The positive side, represented by $r(G)$, implies that a new high-tech zone can create additional economic value. The negative side, represented by $g_{i} \cdot v<0$, however, indicates that a new high-tech zone deceases the economic value engendered by established high-tech zones due to competitions. Therefore the optimization condition should appear when marginal utility equals to marginal cost. Since every regional government holds the systematic position with each other, then because

$$
\begin{gathered}
\frac{\partial^{2} \pi_{i}}{\partial g_{i}^{2}}=2 v^{\prime}(G)+g_{i} v^{\prime \prime}(G)<0 \\
\frac{\partial^{2} \pi_{i}}{\partial g_{j} \partial g_{i}}=v^{\prime}(G)+g_{i} v^{\prime \prime}<0
\end{gathered}
$$

we can come out with the following result:

$$
\frac{\partial g_{j}}{\partial g_{i}}=-\frac{\frac{\partial^{2} \pi_{i}}{\partial g_{j} \partial g_{i}}}{\frac{\partial^{2} \pi_{i}}{\partial g_{i}^{2}}}<0
$$

The above equation indicates that the optimization number of high-tech zones for the particular regional government $\mathrm{i}$ is decreasing as other regional governments increase their numbers of high-tech zones. The Nash Equilibrium for all players will then be $^{*}{ }^{*}=\left(g_{1}, \cdots, g_{i}^{*}, \cdots, g_{n}^{*}\right)$. At this point, the sum of the number of regional high-tech zones is $G^{*}=\Sigma g_{i}^{*}$.

Under the existing promotion tournament system, regional governments choose the number of high-tech zones based on their own interest instead of the social welfare maximization. Therefore we can compare $\mathrm{G}^{*}$ with G0 (the optimization number) to test whether the promotion tournament will lead to the duplicate construction of high-tech zones.

$\mathrm{G}^{*}$ is calculated by adding each F.O.C condition together and the result is as the following:

$$
v\left(G^{*}\right)+\frac{G^{*}}{n} v^{\prime}\left(G^{*}\right)=c
$$

G0, the sum of regional high-tech zones chosen to maximize social welfare is on the other hand calculated through the following equation and its F.O.C condition is calculated to be equation (2).

$$
\max _{G}[G v(G)-G c] v\left(G^{0}\right)+G^{0} v^{\prime}\left(G^{0}\right)=c
$$

By comparing equation (1) and equation (2), we can easily come out with the $\operatorname{result}_{G}{ }^{0}<G^{*}$.

Therefore, based on the above reasoning, we propose our hypothesis as following:

Hypothesis 1a: There exists a negative relationship between regional GDP level and the degree of duplicate constructions in local high-tech zones.

Duplicate constructions of high-tech zones in certain area will usually lead to over-competition for capital, human talent and government's favorable policy, which impair the efficiency of resource allocation and further adversely influence the performance of high-tech zones. In addition, once the high-tech zone is established, it should be kept as a certification for political achievement and doesn't have access to exit. With limited resources 
and constrained survival requirement, the duplicate construction of high-tech zones will be accompanied with under-exploitation of high-tech zones and considerable idle resources, which leads to a higher investment cost and is detrimental to the performance of local high-tech zones. Therefore, based on the above reasoning, we propose our hypothesis as following:

Hypothesis 1b: There exists a negative relationship between the degree of duplicate constructions in local high-tech zones and their performance.

\subsection{Pressure to Attract Investments, Quality of Industrial Configuration and Performance Implication}

While the duplicate construction of high-tech zones generally represent the ex ante government intervention to local high-tech zones, the pressure to attract sufficient investment to keep the operation of over-crowded high-tech zones confronted by regional government often leads to the ex post government intervention to local high-tech zones. While the duplicate construction of high-tech zones already results in an over-supply of such productions with high sunk cost, the pressures to attract investment for the established high-tech zones undoubtedly change into the fierce competition for attracting outside investments among regional governments. Since government officials out of their own interest often pay more attention to short-term economic performance, especially the period they are/were in charge, the pursuit for the quality of investment may be overwhelmed by the pursuit of the quantity. Such a myopia behavior will lead to an ignorance of industry relatedness which impedes the formation of industry agglomeration in the zone and a lack of long-term development plan which emphasizes the sustainability of the high-tech zones' performance. We also use a dynamic model to elaborate how the pressure to attract investment will influence the quality of in-zone industrial configuration.

Assuming there are two regional governments, A and B. The high-tech zones in their area both have room for new enterprises due to the duplicate construction. Suppose there is a firm $X$, whose position is neither in accordance with high-tech zone A nor with high-tech zone B. Now the firm X wants to enter either of the high-tech zones. The entrant of firm $\mathrm{X}$ will bring a regional government two kinds of benefits. On the one hand, the entrant of firm A will increase the local taxation income by contributing a lot to the tax. On the other hand, the entrant of firm A will also bring employment opportunity and better utilize the resources invested to the high-tech zone. For regional government A and B, due to the loan pressure, the per unit cost for unexploited land and other fixed resource is $\mathrm{C}$. During the negotiation process, regional governments possess the right to authorize certain degree of favorable policy, captured by $Y_{a}, Y_{b}\left(T+G \geq Y_{a}, Y_{b}>0\right)$. The favorable policy, on the other word, equals to a cost of regional government.

Based on the above assumptions, we can conclude the reaction function for both A and B since they are systematic. Here we choose B as an example to develop its reaction function. Obviously the firm X will make the decision by comparing the favorable policy each regional government gives. If the firm $\mathrm{X}$ chooses to enter in the high-tech zones in $\mathrm{A}$, then $\mathrm{A}$ gains ${ }^{T+G-C-Y_{a}}$. If the firm X chooses to enter in high-tech zones in $\mathrm{B}$, then $\mathrm{A}$ gains ${ }^{-} C$. Therefore, if A gives a favorable policy $Y_{a}$ as $T+G>Y_{a} \geq 0$, based on game theory, B will absolutely gives a slightly attractive favorable policy $Y_{b}$ to gain $T+G-C-Y \mathrm{~b}$ instead of lost $\mathrm{C}$. This process will not stop until A gives a favorable policy as $Y_{a}=T+G$. Therefore we can get the reaction function for B as following:

$$
Y_{b}=\left\{\begin{array}{cc}
Y_{a}+\varepsilon, & 0<Y_{a}<T+G \\
Y_{a}, & Y_{a}=T+G \\
<Y_{a}, & Y_{a}=T+G
\end{array}\right.
$$

positions, the reaction function for $\mathrm{A}$ is:

Since A and B are in systematic

$$
Y_{a}=\left\{\begin{array}{cc}
Y_{b}+\varepsilon, & 0<Y_{b}<T+G \\
Y_{b}, & Y_{b}=T+G \\
<Y_{b}, & Y_{b}=T+G
\end{array}\right.
$$

The Nash Equilibrium is the intersection of the reaction function for $\mathrm{A}$ and $\mathrm{B}$, which is $Y_{b}=Y_{a}=T+G$. According to such results, when regional governments are confronted with the pressure to attract investment for the high-tech zones in its area, the profit brought by the firm will induce the regional governments to bid for a lower price and hence causes vicious competition for investments, not even to mention the careful selection for industry relatedness, resource synergy and long-term scheme for in-zone industrial configuration. Therefore, we 
propose our hypothesis as following:

Hypothesis 2a: There exists a negative relationship between the level of pressure to attract investment and the quality of in-zone industrial configuration.

The low-quality of in-zone industrial configuration will adversely influence the performance of high-tech zones through the following mechanisms. Firstly, under the pressure to attract investment, the regional government often rushes to the quantity of collection while neglecting the factor endowment variation embedded in different firms. Such myopia behaviors usually results in competitive relationship among in-zone firms rather than complementary relationship which is supposed to form. Secondly, the ignorance of industrial relatedness can make the high-tech zone a simple collection of numbers of firms without engendering the synergistic effect from firm interdependencies. What's more, those firms which involve high pollution or on the edge of their life cycle will heavily constrain the future development of the high-tech zones. Therefore, we propose our hypothesis as following:

Hypothesis $2 \mathrm{~b}$ : There exists a positive relationship between the quality of in-zone industrial configuration and the performance of high-tech zones.

\section{Procedures for Collecting Data}

\subsection{Data Selection and Sample}

We choose the high-tech zones in China as our research object. From 2006, Chinese Commerce Department began to record the data of high-tech zones. In this paper we choose all recorded high-tech zones in 2006 and 2007 to conduct our empirical test. Excluding those observations which lack the data in some key variables, we finally get a sample of 106 high-tech zones, 53 in 2006 and 53 in 2007.

\subsection{Dependent Variable}

The dependent variable in this paper includes the degree of duplicate construction of high-tech zones, the quality of in-zone industrial configuration and the performance of high-tech zones.

The degree of duplicate construction of high-tech zones (Duplicate) is measured as the number of high-tech zones in the same province. This data can be acquired through looking up the website www.cadz.org.cn which descries related information about high-tech zones in China.

The quality of in-zone industrial configuration (Configure) is measured as the degree of industry agglomeration. In this paper we borrow the way to measure such indexes from Zhang and Zhang (2005), Wang and Yang (2008) and obtain required information by looking up the official website of every high-tech zones. The accurate measurement of this variable is Industry $\sum_{i=1}^{M} P_{i}$ where Pi refers to the ratio of output value of dominant industries and output value of all industries.

We adopt an integrative method to measure the performance of high-tech zones (Perform), including a number of indicators related to social performance and economic performance. The measurement of social performance is comprised of the number of employees, chemistry oxygen demand (COD), pollution level, the number of patents, and the ratio of the zone's GDP and the province's GDP. The measurement of economic performance is comprised of the overall industrial output value, taxation income, the number of foreign investment, the number of export and import and the number of high-tech firms in the zone.

\subsubsection{Independent Variable}

The GDP level (GDP) is measured as the provincial GDP in that year and such information is acquired from Sino Fin Database developed by Chinese Center of Economic Research (CCER). The time pressure to attract investments for high-tech zones (Taxrate) is reflected by the final tax reduction offered by regional government. Therefore we use the efficient tax rate as an indicator for this independent variable.

\subsubsection{Control Variables}

We set two series control variables for the two set of hypothesis. In the model to test the government intervention's influence on the characteristics of high-tech zones performance, we use the indicators for economic performance, which includes the fiscal revenue (Revenue) and deficit rate (Deficit), indicators for environmental condition, which includes the city road traffic mileage (Traffic), the price of electricity (Electric) and the marketization index (Marindex) and location (location) as control variables. In the model to test the influence of high-tech zones' characteristics to the performance, we use capacity of electric power supply (Infra), the number of in-zone personnel training institutions (Human), the stock of capital allocated to support technological development (Innovate), the quality of managerial service (Service), the location (location) and 
scale (scale) as control variables.

\title{
3.3 Models
}

The first model which tests hypothesis $1 \mathrm{a}$ and hypothesis $2 \mathrm{a}$ and the second model which tests hypothesis $2 \mathrm{~b}$ and hypothesis $2 \mathrm{~b}$ is an OLS regression as following.

Model 1:

Duplicate $($ Configure $)=\alpha+\beta 1 *$ GDP $($ Taxrate $)+\beta 2 *$ Revenue $+\beta 3 *$ Deficit $+\beta 4 *$ Traffic $+\beta 5^{*}$ Electric $+\beta 6^{*}$ Marindex $+\beta 7^{*}$ location $+\mu$

Model 2:

Perform $=\alpha+\beta 1^{*}$ duplicate (configure) $+\beta 2 *$ Infra $+\beta 3^{*}$ Human $+\beta 4^{*}$ Innovate $+\beta 5^{*}$ Service $+\beta 6^{*}$ Location $+\beta 7^{*}$ Scale $+\mu$

\section{Results}

The correlation matrixes of the variables in the first model and the second model are presented as following in the table 1 and table 2.

\author{
Insert Table 1- here \\ Insert Table 2- here
}

The results for regression are presented in Table 3 and Table 4. As is shown in table 3, the coefficient of GDP is significantly negative, therefore supporting the negative relationship between regional GDP level and the degree of duplicate constructions predicted in hypothesis 1 a. As is shown in table 4, the coefficient of duplicate is significantly negative, which is supportive of hypothesis $1 \mathrm{~b}$. Therefore, the first mechanism proposed to influence the performance of high-tech zones is empirically supported: confronting the fierce competition, regional governments which suffer from a low regional GDP level have more incentives to devote to duplicate constructions of high-tech zones to fake their economic achievement. Such political-driven motivation will, on the other hand, be detrimental to the performance of local high-tech zones due to over-competition.

\section{Insert Table 3- here \\ Insert Table 4- here}

In addition, the second mechanism is also empirically supported. As is shown in table 3, the coefficient of Taxrate is significantly positive, which implies a negative relationship between the time pressure confronted by the regional government and the quality of in-zone industrial configuration since the Taxrate indicates less favorable policy as tax reduction and the larger time pressure it is, the lower the Taxrate will be. Therefore, the positive coefficient is supportive of the negative relationship as expected in hypothesis $2 \mathrm{a}$. As is shown in table 4 , the coefficient of configure is significantly positive, which implies there exists a positive relationship between the quality of in-zone industrial configuration and the performance of high-tech zones as predicted in hypothesis $2 \mathrm{~b}$. Therefore the second mechanism proposed in this paper is also empirically supported: the time pressure confronted by regional government to attract investment for established high-tech zones induces the regional government to concentrate on the quantity of investment rather than the quality, therefore causing a deteriorating quality of in-zone industrial configuration, which threatens the performance of high-tech zones by weakening the synergistic effect.

\section{Conclusions and Implications}

This paper discusses how the institutional environment affects the performance of high-tech zones under institution imperfection. Specifically, based on Institutional Economics and Game Theory, we build a model to analyze how government intervention affects the performance of high-tech zones, in which government intervention leads to a high degree of duplicate constructions of high-tech zones and a low quality of in-zone industrial configuration which further impair the performance of local high-tech zones due to over-competition.

Existing researches about high-tech zones mainly tried to elaborate the superiority of high-tech zones as its proficiency in promoting knowledge transfer and facilitating high-tech entrepreneurship. However, when the form of high-tech zone is transferred from developed countries to transition economy, how the institutional imperfection influences the performance of high-tech zones remains an unnoticed field. This paper contributes to the research about high-tech zones by integrating Institutional Theory and Game Theory into the analysis and provides practical implication for both regional government and enterprises in high-tech zones.

However, our research also suffers from some limitations. One important limitation is that we only use data from 
2006 to 2007. Two years is quite a short time and the conclusion hence may be questioned of its consistency and continuity. However, based on our knowledge, there is no particular policy change or regulation amendment regarding high-tech zones in both 2006 and 2007, therefore we have the confidence that the data in 2006-2007 is representative of the general time periods in the development of Chinese high-tech zones. Also, it would be interesting for future researches to collect data spanning longer period and check whether there are disparities in conclusions. Another important limitation is that we only collect data in Chinese context and thus making the conclusion suffers from the question of generalizability. While china is a good example of transitional economy, it is reasonable to argue that other transitional economies differ from China according to their own tradition, culture and law system. Therefore great caution is required when the conclusion is applied to other contexts. However, future researches may conduct cross-context comparative studies to testify the validity of the conclusions in other contexts.

\section{Acknowledgement}

Ke Xiong, Xiwei Yi and Xiaolong Liu made equal contribution to this article.

\section{References}

AnnaLee Saxenian. (1990). Regional Networks and the Resurgence of Silicon Valley. California Management Review.

Hsien-Che Lai \& Joseph Z. Shyu. (2005). A Comparison of Innovation Capacity at Science Parks across the Taiwan Strait: the Case of Zhangjiang High-Tech Park ad Hsinchu Science-based Industrial Park. Technovation, 25, 805-813. http://dx.doi.org/10.1016/j.technovation.2003.11.004

Jianhua, Zhang., \& Shujing, Zhang. (2006). Research on the Criterion of Identifying Industrial Cluster. China Soft Science, 3.

Li-an, Zhou. (2007). Governing China's Local Officials: An Analysis of Promotion Tournament Model. Economic Research, 7.

Martin Kenney., \& Urs Von Burg. (1999). Technology, Entrepreneurship and Path Dependence: Industrial Clustering in Silicon Valley and Route 128. Industrial and Corporate Change, 8(1). 1999. http://dx.doi.org/10.1093/icc/8.1.67

Porter, Michael. (1990). The Competitive Advantage o Nations. New York: Free Presss. 
Table 1. Correlation of variables in the first model

\begin{tabular}{|c|c|c|c|c|c|c|c|c|c|c|}
\hline & Duplicate & GDP & Configure & Taxrate & Revenue & Deficit & Traffic & Electric & Marindex & District \\
\hline Duplicate & 1.000 & & & & & & & & & \\
\hline GDP & $\begin{array}{c}-0.698 * * \\
(0.000)\end{array}$ & 1.000 & & & & & & & & \\
\hline Configure & $\begin{array}{c}0.291 \\
(0.055)\end{array}$ & $\begin{array}{l}-0.028 \\
(0.856)\end{array}$ & 1.000 & & & & & & & \\
\hline Taxrate & $\begin{array}{l}-0.088 \\
(0.568)\end{array}$ & $\begin{array}{l}-0.146 \\
(0.344)\end{array}$ & $\begin{array}{l}0.894 * * \\
(0.000)\end{array}$ & 1.000 & & & & & & \\
\hline Revenue & $\begin{array}{c}0.599 * * \\
(0.000)\end{array}$ & $\begin{array}{c}0.968^{* *} \\
(0.000)\end{array}$ & $\begin{array}{l}0.256^{*} \\
(0.044)\end{array}$ & $\begin{array}{l}-0.335^{*} \\
(0.014)\end{array}$ & 1.000 & & & & & \\
\hline Deficit & $\begin{array}{c}-0.537 * * \\
(0.000)\end{array}$ & $\begin{array}{c}-0.831 * * \\
(0.000)\end{array}$ & $\begin{array}{l}-0.064 \\
(0.647)\end{array}$ & $\begin{array}{c}0.150 \\
(0.285)\end{array}$ & $\begin{array}{c}-0.802 * * \\
(0.000)\end{array}$ & 1.000 & & & & \\
\hline Traffic & $\begin{array}{c}0.013 \\
(0.093)\end{array}$ & $\begin{array}{l}-0.198 \\
(0.197)\end{array}$ & $\begin{array}{c}0.163 \\
(0.291)\end{array}$ & $\begin{array}{l}-0.173 \\
(0.263)\end{array}$ & $\begin{array}{l}-0.237 \\
(0.122)\end{array}$ & $\begin{array}{l}0.291 \\
(0.055)\end{array}$ & 1.000 & & & \\
\hline Electric & $\begin{array}{c}0.600 * * \\
(0.000)\end{array}$ & $\begin{array}{c}0.449 * * \\
(0.002)\end{array}$ & $\begin{array}{l}0.177 \\
(0.251)\end{array}$ & $\begin{array}{l}-0.253 \\
(0.097)\end{array}$ & $\begin{array}{l}0.383 * \\
(0.010)\end{array}$ & $\begin{array}{c}-0.457^{* *} \\
(0.002)\end{array}$ & $\begin{array}{l}-0.028 \\
(0.856)\end{array}$ & 1.000 & & \\
\hline Marindex & $\begin{array}{c}0.705^{* *} \\
(0.000)\end{array}$ & $\begin{array}{c}0.778^{* *} \\
(0.000)\end{array}$ & $\begin{array}{l}0.195^{*} \\
(0.031)\end{array}$ & $\begin{array}{l}-0.314 * \\
(0.022)\end{array}$ & $\begin{array}{c}0.684 * * \\
(0.000)\end{array}$ & $\begin{array}{c}-0.656^{* *} \\
(0.000)\end{array}$ & $\begin{array}{l}-0.146 \\
(0.344)\end{array}$ & $\begin{array}{c}0.416^{* *} \\
(0.005)\end{array}$ & 1.000 & \\
\hline District & $\begin{array}{c}0.452 * * \\
(0.001)\end{array}$ & $\begin{array}{c}0.638^{* *} \\
(0.000)\end{array}$ & $\begin{array}{c}0.141 \\
(0.314)\end{array}$ & $\begin{array}{l}-0.213 \\
(0.126)\end{array}$ & $\begin{array}{c}0.603 * * \\
(0.000)\end{array}$ & $\begin{array}{c}-0.778 * * \\
(0.000)\end{array}$ & $\begin{array}{l}-0.088 \\
(0.568)\end{array}$ & $\begin{array}{l}0.430 * * \\
(0.004)\end{array}$ & $\begin{array}{c}0.575 * * \\
(0.000)\end{array}$ & 1.000 \\
\hline
\end{tabular}

Table 2. Correlation of variables in the second model

\begin{tabular}{|c|c|c|c|c|c|c|c|c|c|}
\hline & Perform & Duplicate & Configure & Infra & Human & Innovate & Service & Location & Scale \\
\hline Perform & 1.000 & & & & & & & & \\
\hline Duplicate & $\begin{array}{c}-0.134^{* *} \\
(0.005)\end{array}$ & 1.000 & & & & & & & \\
\hline Configure & $\begin{array}{c}0.534^{* *} \\
(0.005)\end{array}$ & $\begin{array}{c}0.291 \\
(0.055)\end{array}$ & 1.000 & & & & & & \\
\hline Infra & $\begin{array}{l}0.456^{*} \\
(0.043)\end{array}$ & $\begin{array}{c}0.550^{* *} \\
(0.000)\end{array}$ & $\begin{array}{c}0.199 \\
(0.154)\end{array}$ & 1.000 & & & & & \\
\hline Human & $\begin{array}{c}0.343^{* *} \\
(0.000)\end{array}$ & $\begin{array}{c}0.245 \\
(0.277)\end{array}$ & $\begin{array}{c}0.266 \\
(0.054)\end{array}$ & $\begin{array}{c}0.395^{* *} \\
(0.003)\end{array}$ & 1.000 & & & & \\
\hline Innovate & $\begin{array}{c}0.298 \\
(0.417)\end{array}$ & $\begin{array}{c}0.358^{* *} \\
(0.008)\end{array}$ & $\begin{array}{c}0.130 \\
(0.352)\end{array}$ & $\begin{array}{c}0.519^{* *} \\
(0.000)\end{array}$ & $\begin{array}{c}0.556^{* *} \\
(0.000)\end{array}$ & 1.000 & & & \\
\hline Service & $\begin{array}{c}0.212 \\
(0.632)\end{array}$ & $\begin{array}{c}-0.123 \\
(0.380)\end{array}$ & $\begin{array}{l}-0.249 \\
(0.072)\end{array}$ & $\begin{array}{c}0.246 \\
(0.076)\end{array}$ & $\begin{array}{c}0.077 \\
(0.581)\end{array}$ & $\begin{array}{c}0.076 \\
(0.589)\end{array}$ & 1.000 & & \\
\hline Location & $\begin{array}{c}0.371 \\
(0.323)\end{array}$ & $\begin{array}{c}0.050 \\
(0.724)\end{array}$ & $\begin{array}{l}-0.241 \\
(0.082)\end{array}$ & $\begin{array}{c}0.450^{* *} \\
(0.001)\end{array}$ & $\begin{array}{c}0.421^{* *} \\
(0.002)\end{array}$ & $\begin{array}{c}0.363^{* *} \\
(0.007)\end{array}$ & $\begin{array}{c}0.022 \\
(0.878)\end{array}$ & 1.000 & \\
\hline Scale & $\begin{array}{c}0.654^{* *} \\
(0.000)\end{array}$ & $\begin{array}{c}0.424 * * \\
(0.002)\end{array}$ & $\begin{array}{l}-0.173 \\
(0.216)\end{array}$ & $\begin{array}{c}0.652^{* *} \\
(0.000)\end{array}$ & $\begin{array}{l}0.288^{*} \\
(0.036)\end{array}$ & $\begin{array}{c}0.632 * * \\
(0.000)\end{array}$ & $\begin{array}{c}0.214 \\
(0.123)\end{array}$ & $\begin{array}{c}0.219 \\
(0.115)\end{array}$ & 1.000 \\
\hline
\end{tabular}


Table 3. Regression result for the first model

\begin{tabular}{|c|c|c|}
\hline Constant & $\begin{array}{c}\text { duplicate } \\
\left(-40.581^{* *}\right. \\
(-0.192)\end{array}$ & $\begin{array}{c}1.222^{* * *} \\
(9.157)\end{array}$ \\
\hline GDP & $\begin{array}{c}-33.540^{* *} \\
(-2.040)\end{array}$ & \\
\hline Taxrate & & $\begin{array}{c}3.488^{*} \\
(1.467)\end{array}$ \\
\hline Revenue & $\begin{array}{c}50.485^{*} \\
(-1.288)\end{array}$ & $\begin{array}{c}0.008 \\
(0.921)\end{array}$ \\
\hline Deficit & $\begin{array}{c}-12.255 \\
(-0.814)\end{array}$ & $\begin{array}{c}0.002 \\
(0.187)\end{array}$ \\
\hline Traffic & $\begin{array}{c}9.334 \\
(0.882)\end{array}$ & $\begin{array}{c}-0.003 \\
(-0.356)\end{array}$ \\
\hline Electric & $\begin{array}{c}73.072 * * * \\
(2.809)\end{array}$ & $\begin{array}{c}-0.014 \\
(-0.670)\end{array}$ \\
\hline Marindex & $\begin{array}{c}9.335 \\
(1.419)\end{array}$ & $\begin{array}{c}0.008^{*} \\
(1.768)\end{array}$ \\
\hline District & -0.145 & -0.005 \\
$(0.011)$ & $(-0.457)$ \\
\hline $\mathrm{N}$ & 106 & 106 \\
\hline F-value & 11.317 & 73.501 \\
\hline Adjusted $\mathrm{R}^{2}$ & 0.627 & 0.922 \\
\hline
\end{tabular}

Table 4. Regression Result for the second model

\begin{tabular}{|c|c|c|}
\hline \multirow{2}{*}{ Constant } & \multicolumn{2}{|c|}{ performance } \\
& $\begin{array}{c}3.132^{* *} \\
(4.267)\end{array}$ & $\begin{array}{c}2.594^{* *} \\
(4.620)\end{array}$ \\
\hline \multirow{2}{*}{ duplicate } & $\begin{array}{c}-2.381^{*} \\
(-1.342)\end{array}$ & \\
\hline \multirow{2}{*}{ configure } & & $\begin{array}{c}3.216^{* *} \\
(3.784)\end{array}$ \\
\hline \multirow{2}{*}{ Infra } & $\begin{array}{c}-0.321^{*} \\
(-0.034)\end{array}$ & $\begin{array}{c}0.176 \\
(0.389)\end{array}$ \\
\hline \multirow{2}{*}{ Human } & $\begin{array}{c}0.456 \\
(0.236)\end{array}$ & $\begin{array}{c}0.567 \\
(0.230)\end{array}$ \\
\hline \multirow{2}{*}{ Innovate } & $\begin{array}{c}0.323^{* *} \\
(2.012)\end{array}$ & $\begin{array}{c}0.391^{*} \\
(2.326)\end{array}$ \\
\hline \multirow{2}{*}{ Service } & $\begin{array}{c}1.219 \\
(0.139)\end{array}$ & $\begin{array}{c}-0.180 \\
(-0.242)\end{array}$ \\
\hline \multirow{2}{*}{ Location } & $\begin{array}{c}0.032 \\
(0.374)\end{array}$ & $\begin{array}{c}0.054 \\
(0.257)\end{array}$ \\
\hline \multirow{2}{*}{ Scale } & $0.390^{* * *}$ & $0.413^{* * *}$ \\
& $(4.254)$ & $(4.419)$ \\
\hline $\mathrm{N}$ & 106 & 106 \\
\hline F-value & 12.436 & 12.324 \\
\hline Adjusted $\mathrm{R}^{2}$ & 0.622 & 0.488 \\
\hline
\end{tabular}

